\title{
On the Lexical Features of New Zealand English
}

\author{
YAN Hong-cai, SONG Yin-qiu \\ Jilin Agricultural University, Changchun, China
}

\begin{abstract}
New Zealand English has a history of more than 200 years. Compared with other English variants, New Zealand English vocabulary has formed its own unique linguistic characteristics in terms of Maori vocabulary, compound words, changes in lexical meaning, acronyms, slang, and idioms, etc. A study of the lexical features of New Zealand English is helpful to our comprehensive understanding of English as a universal language. With the development of economic and cultural exchanges between China and New Zealand, it is of great practical significance to the study of New Zealand English.
\end{abstract}

Keywords: New Zealand English, Maori, vocabulary, features

\section{Introduction}

Language is the product of social development. It must be closely related to the whole history of a country, a nation or a region. In 1769, British navigator James Cook discovered New Zealand and landed for the first time at Gisborne on the east coast of New Zealand North Island. After that, immigrants gradually moved to New Zealand and began to form New Zealand English. New Zealand English has long been linked to British English because of colonization, immigration, trade, and culture. However, due to social, historical, and cultural constraints, the new regional environment and social characteristics have changed New Zealand English. On the one hand, New Zealand English inherits and absorbs British English, Australian English, and Maori language, and also has a close relationship with them. On the other hand, a large number of immigrants of European descent from different ethnic and cultural backgrounds, together with the immigrants from early Australia, formed the majority of New Zealanders (Zhu \& Yang, 2000). It makes New Zealand English construct specific language form in New Zealand's unique historical background, geographical location, and social combination, forming some characteristics different from British English. In the communication with the local Maori, the two languages and two cultures have merged, infiltrated, and innovated each other, developed the traditional British English, and made New Zealand English form its own characteristics, which are different from other English variants. These changes are most evident in the language of construction materials-vocabulary (Chen, 1998). The lexical features of New Zealand English are discussed as follows.

Acknowledgement: This paper was sponsored by the research foundation from Jilin Province Social Science Foundation Project (Grant No. 2017B28).

YAN Hong-cai, Master, Professor, College of Foreign languages, Jilin Agricultural University, Changchun, China.

SONG Yin-qiu, Ph.D., Professor, College of Foreign languages, Jilin Agricultural University, Changchun, China. 


\section{Lexical Features}

\section{Maori Vocabulary}

Although New Zealand's mainstream society is made up of British immigrants, Maori make up about 15 percent of the population (2013). In colonial history, the fate of the Maori in New Zealand is different from that of the Indians of the United States and the Aborigines of Australia. The Maori had long been associated with whites in social life and even marriage. Because of the strong integrity of Maori culture, the roots of its native language and culture were not cut off under colonial rule. Therefore, Maori in New Zealand are not only ethnic minorities, but also cultural minorities. Maori culture has always been a place in New Zealand. With the revival of Maori culture in the 1980s, especially the establishment of the Maori Language Committee, Maori has become more and more important in radio and television since the New Zealand government made Maori an official language. There is no doubt that Maori will have a growing impact on New Zealand English (Zhang, 2000). In a society where two languages coexist, the mutual penetration and fusion of languages is self-evident. Many Maori words entered New Zealand English, which greatly enriched the expressiveness of English (Chen, 1998).

The Maori vocabulary in New Zealand English is mainly concentrated in three aspects (O’Connor, 1992).

Vocabulary on Maori socio-cultural life. For example, haka (Maori war dance), whare (hut, straw shed), hangi (ground stove), waipiro (alcoholic beverages), hokonui (illegally manufactured or sold), mana (supernatural power, authority), korero (talk, discussion), marare (get-together place), hui (aggregation) (Liu, 1995), kiaora (hello), Maoritanga (Maori culture and custom), tiki (a jade ornament hanging from the neck), poi (flax embroidered ball for ball throwing), puku (stomach), taihoa (just a moment), puckeroo (broken, damaged), etc.

Vocabulary of local plant and animal communities. For example, totara (coniferous wood), kari (shell pine tree), kiwi fruit or kiwi berry, kumara (sweet potato, potato), kowhai (fourwing sophora), rata (New Zealand evergreen tree), kauri (Gali tree), matai (Pinus thunbergii Parl), hutukawa (Christmas tree), manuka (manuca trees), rimu (Pinus koraiensis), kapo (osprey parrot), kiwi (snipe), moa (Dinornis), Kotuku (heron), pukeko (purple water chicken), huhu (hu beetle) (Liu, 1995), katipo (spider), etc.

Proper nouns. For example, Maori (the indigenous/native people of New Zealand, the first inhabitants of New Zealand), matai (chief), wahine (Maori woman), pakeha (a person who is not of Maori descent especially a white person), Aotearoa (New Zealand), Witangi (a village in northeastern North Island, New Zealand), Porirua (a port city), Paraparaumu (a major town on the coast of Capetti, New Zealand), etc. These Maori words have a common feature, all ending in vowels, which is very easy to read.

\section{Compound Words in New Zealand English}

The compound words in New Zealand English are often related to local physical geography, economy, and culture. These words have been incorporated into New Zealand English with the help of Maori native language or other forms of combination.

Vocabulary for plants, animals. Some animals or plants are endemic to New Zealand. For example, bellbird (a tropical bird of the genus Procnias having a bell-like call), cockatoo (a bird of the parrot family, with a large row of feathers standing up on its head), leatherjacket (a species of jack/fish in the family Carangidae), butterfish (slippery scaleless food fish), morepork (a small brown owl, also called the ruru or Tasmanian spotted 
owl), cabbagetree (any of a number of palmlike trees that resemble a cabbage in some way), whitepine (a pine tree especially in having needles in bundles/clusters of five), fantail (fan-tailed flycatcher), etc. These words have corresponding nouns respectively in Maori dialect, and these compound words once existed simultaneously in New Zealand English. After a period of evolution, Maori words were gradually eliminated, but the compound words were preserved (Zhu \& Yang, 2000).

Agricultural vocabulary. Agriculture plays a very important role in the New Zealand economy, especially animal husbandry. New Zealand was originally an agricultural and animal husbandry country, especially the animal husbandry, the early immigrants in addition to gold mining which is engaged in animal husbandry. New Zealand is still one of the most famous animal husbandry countries in the world. Therefore, there are many words about animal husbandry in New Zealand English. For example, high country (sheep farm), stockholder (livestock keeper), run holder (shepherd owner), cow-cocky (a small dairy rancher), stock rider (a herder on horseback), sheep run (sheep farm), sheep station (wool shearing yard), woolclip (annual wool yield), woolshed (wool packing room, wool processing plant), corriedale (a breed of sheep developed in New Zealand and raised for mutton and wool), etc. These words are hard to find in British English (Zhu \& Yang, 2000).

Other New Zealand compounds. For example, Moa-hunte (dinornis hunter), cattlestop (livestock furrow), dwag man (a wandering man with a bag on his back), lamb’s fry (lamb’s edible offal), deer culler (professional deer hunter), tar-sealed (asphalt macadam pavement), watersider (wharf worker), jetboat (jet speedboat), glory box (dowry box), wet-back (water heating), private hotel (a hotel operating alcohol products without a license), small goods (petty commodities), etc. Some of these terms are unique to New Zealand, and some of them are found in other countries or regions, but they are used differently. For instance, Waterside means "waterfront, riverside, lakeside, seaside” in British English but without the meaning of "wharf worker” (Zhu \& Yang, 2000).

\section{Changes in Lexical Meaning in New Zealand English}

Unique meaning of New Zealand English words. The meanings of words in New Zealand English are somewhat different from those in British or American English. The same words often derive new meanings in New Zealand English and have unique meanings which are not found in British English. This is also due to the local special human environment, geographical environment, history and current situation (Gordon \& Deverson, 1985). The following are some examples.

In British English, pottle is traditionally used to refer to small wicker baskets that hold strawberries, as well as to "a basket of strawberries"; but in New Zealand English, it has a very different meaning from British English: It refers to cartons used for fried potato chips; or it is used to refer to a box of chips.

Station used to mean that some of New Zealand's earliest pastures were run by criminals who were monitored, called station. In addition to the general meaning of British English, private ranches in New Zealand can now be called station.

Muster is a military term intended for gathering and concentrating, but in New Zealand English it also refers to sheep and herds. Mob means mobster, and it also refers to herd or crowd in New Zealand English. Duchesse in British English refers only to a female duke or duke's wife, but in New Zealand it can be used to refer to a dresser with a rotatable mirror. Other words include: Run refers to a piece of grazing land, which refers specifically to the sheep farm (Chen, 1998); bail is a shelf used to lift the head of a sheep during milking; Race refers to a very 
narrow fence through which livestock can only pass one end; draft is the separation of an animal from a herd; shed refers to the separation of sheep by a sheepdog; do refers to taking care of sheep and feeding them. These words are given a special meaning in New Zealand English, and the reasons are very much related to the local economic life, especially the obvious influence of agriculture and animal husbandry.

The phenomenon of identical words of different meanings with British English. When a language is transplanted into a new geographical and cultural environment, the language changes quietly and forms some new regional features. Many words in New Zealand English tend to have completely different or partially different features compared with their parent British English.

In British English, creek refers to a small bay or harbor leading to the sea. But in New Zealand English, it refers to a tributary of a great river, or to a small river or stream (Chen, 1998).

Bush means "shrub” in British English and "forest” in New Zealand (Wang, 1994).

Although the word white in English has a positive connotation, it has a broader associative meaning in New Zealand English. It is often seen as a synonym for "charity, purity, honesty and reliability”, and its connotations are often exaggerated.

Bloody in New Zealand English has semantic function, which is equivalent to that of "very". Apparently, the tone of a bloody foolish old man (= a very foolish old man) is much stronger than that of a foolish old man. In British English, the term "bloody" means "gory", or "conflict with serious casualties": the bloody hands of the criminal, the bloody five-day battle ( $\mathrm{Li}, 1998)$.

Paddock in British English means "a small, usually enclosed field for pasturing or exercising animals" or "racetrack", that is to say, a small plot of land enclosed only near a house or stable, usually used for grazing or horse training; while in New Zealand English, the term "paddock" means a piece of land enclosed by a fence, of varying sizes or uses; and in Australian English the word also contains this meaning (Wang, 1994).

Hurrah (hooray), in British English only expresses joy, satisfaction, encouragement, etc. But in New Zealand English, it can also be a familiar expression of good-bye between friends (Chen, 1998).

The phenomenon of synonymous dissimilar words with British English. Another feature of New Zealand English is that it uses words different from British English to express the same thing. For example, New Zealand has introduced from Australia a small animal called opossum or possum. But New Zealanders in spoken English call it joey more often than not. In Australia, however, only refers to young kangaroos; in British English, the slang term refers to only three or four pence coins. It can be seen that the term has a special referential meaning in New Zealand (Chen, 1998).

"People who run used cars" are called used-car dealer or second-hand car dealer in British English, but in New Zealand English it's expressed by a very unique word "birdcage boy". The field of exhibition of the used cars is usually surrounded by wire, and the used car dealer moves in the fence all day, like a bird in a cage, so there is a lively, vivid metaphor.

The dome often worn by old English gentlemen is called bowler hat in British English, derby hat in American English, and bun hat or hard hitter in New Zealand English.

In British English cattlegrid refers to a fence laid on a gully at the entrance and exit; a man, or a car can get on it; but the animals dare not walk on it. In New Zealand English it is customary to use the word "cattle-stop". 
The kiwifruit mentioned earlier, Chinese gooseberry, is originally used in British English, and the New Zealand Kiwi fruit is now used beyond the limits of the country.

"Replacement" in a team, is expressed in emergency in New Zealand and reserve in British English; New Zealand English uses varsity to express university, while British English uses university to express it (Zhang, 2000); British English uses village for a small community or group of houses in a rural area, while New Zealand English uses township for village.

In terms of "middle school”, British English uses secondary school; American English uses high school, while New Zealand English uses college. For example, Mana College is not "Mana College", but "Mana Middle School" (Wang, 1994).

Mental hospital is called rat factory, which is also a unique expression in New Zealand English.

The phenomenon of synonymous dissimilar words with British English is also reflected in many other words.

\section{Acronyms in New Zealand English}

Due to different national conditions, acronyms in New Zealand English are very distinctive. It is necessary to master the acronyms commonly used in New Zealand, otherwise you will sometimes fail to understand what others are talking about, or the news you are listening to, or the books and newspapers you are reading (Li, 1994).

Abbreviations in daily life include: NZ—New Zealand, NZD—New Zealand Dollars, ACC—Accident Compensation Corporation, AKL-Auckland, ANIAC-Australian and New Zealand Army Corps, BBH—Budget Backpacker Hostels, BYO—bring your own, CER-Closer Economic Relations, CHCH—Christchurch, DBP—Domestic Purposes Benefit, DIY — do it yourself, RSA—Returned Servicemen's Association, WLG-Wellington, YHA-Youth Hostel Association.

\section{Unique Slang and Idioms in New Zealand English}

The richness of the language is reflected in its diversity of expressions. Another feature of the New Zealand English vocabulary is the existence of a great deal of slang and idioms. In daily speaking, people often use some unique expressions to get vivid, novel, and unconventional effects. Many of the slang and idioms in New Zealand English vividly reflect the geographical and humanistic nature of the country.

For example, across the ditch (refers to Australia), bright as a button (it looks new and dynamic), bright spark (smart, focused), bring a plate (everyone brings their own food to share), clean as a whistle (polished), drive around the bend (be too upset to control one's emotions), flat tack (high speed), got the blues (used to describe a sad mood), good on you (you are really good), hard case (stubborn, but not obnoxious), high country (mountain area with inconvenient transportation), hard graft (works hard), in the dogbox (be treated badly, lose favor), like a bomb (rapid), no worries (consenting idioms), on a high (a sense of joy in success), once in a blue moon (rare, hardly), paint the town red (go out to relieve boredom), rough ride (difficult experience), she'll be right (is nothing, to be all right, have all one's wishes) (Wang, 1994), snowed under (generally refers to too much work to be done), to jack up (arrangement, organization, placement), the keg's cut (beer sold out), to take for a ride (to deceives or teases), to make a do of it (succeed), to do one's bun (lose one's temper), to do in (spent all his money), to be in donkey deep (fully involved), under the weather (looks bad, uncomfortable, tired), veggies (vegetables), wop-wops (suburban, rural), yonks (a long time ago), etc. 


\section{Conclusion}

As we all know, English has become a worldwide language. However, different regions of English have their own uniqueness; after more than 200 years of development, New Zealand English has formed its own unique language characteristics. With the increasing frequency of economic and cultural exchanges in the world, understanding and mastering the regional features of English is helpful to the smooth progress of cross-cultural communication. Vocabulary, as the most basic language material, is the first object to be paid attention to. The study of the characteristics of New Zealand English vocabulary is helpful to our comprehensive understanding of English as a world language. With the development of economic and cultural exchanges between China and New Zealand, it is of great significance to study New Zealand English.

\section{References}

Cheng, Q. M. (1998). Lexical features of New Zealand English. Journal of Fuzhou University (Social Sciences Edition), 12(4), 37-40.

Gordon, M. E., \& Deverson, A. J. (1985). New Zealand English. Hong Kong: Hong Kong Press.

Li, G. N. (1994). On New Zealand English. Journal of Guangxi Teachers College (Philosophy and Social Sciences Edition), (1), 76-83.

Li, G. N. (1998). The function of the word bloody in New Zealand English. Journal of Guangxi Teachers College (Philosophy and Social Sciences Edition), (1), 82-85.

Liu, G. H. (1995). Characteristics of English in Australia and New Zealand. Journal of Sichuan Normal University (Philosophy and Social Sciences Edition), (1), 91-93.

O’Connor, J. D. (1992). Better English pronunciation. London: Cambridge University Press.

Wang, Y. X. (1994). On the characteristics of New Zealand English. Journal of Zhangjiakou Teachers College (Social Sciences Edition), (2), 46-48.

Zhang, J. (2000). A probe into the origin and characteristics of New Zealand English. Journal of Anqing Teachers College (Social Sciences Edition), 19(1), 105-108.

Zhu, L. H., \& Yang, J. (2000). A preliminary study of New Zealand English pronunciation and vocabulary. Journal of Hunan Agricultural University (Social Science Edition), (1), 73-75. 